\title{
Fos and Egrl expression in the rat brain in response to olfactory cue after taste-potentiated odor aversion retrieval
}

\author{
David Dardou, ${ }^{1}$ Frédérique Datiche, and Martine Cattarelli \\ Centre Européen des Sciences du Goût, Centre National de la Recherche Scientifique (CESG-CNRS), UMR 5170, 21000 \\ Dijon, France
}

\begin{abstract}
When an odor is paired with a delayed illness, rats acquire a relatively weak odor aversion. In contrast, rats develop a strong aversion to an olfactory cue paired with delayed illness if it is presented simultaneously with a gustatory cue. Such a conditioning effect has been referred to as taste-potentiated odor aversion learning (TPOA). TPOA is an interesting model for studying neural mechanisms of plasticity because of its robustness and rapid acquisition. However, the neural substrate involved in TPOA retrieval has not been well characterized. To address this question, we used immunocytochemical detection of inducible transcription factors encoded by the immediate-early genes Fos and Egrl. Thirsty male rats were conditioned to TPOA learning, and they were submitted to retrieval in the presence of the learned odor $3 \mathrm{~d}$ later. Significant increases in both Fos and Egrl expressions were observed in basolateral amygdala, insular cortex, and hippocampus in aversive rats in comparison with the all the control groups. The pattern of neuronal activity seemed unlikely to be related to the sole LiCl injection. Lastly, opposite patterns of Fos and Egrl were noted in the entorhinal cortex and the central nucleus of amygdala, suggesting a differential involvement of these markers in retrieval of TPOA.
\end{abstract}

Odors are critical cues for rodents since odors give the rodents information about their environment. Odors allow the rodents to escape from predators, to find food, or to avoid consumption of toxic products. Memorization of such information is crucial for animal survival. Moreover, olfactory learning permits a previously neutral cue to acquire significance after having been paired with a biologically relevant reinforcement. Rats can acquire weak aversion when an odor is paired with delayed-illness (Bernstein 1991). In contrast, when an odor is simultaneously presented with a taste cue, rats can develop strong aversion to the odor cue. Such a conditioning has been referred to as tastepotentiated odor aversion (TPOA) learning (Palmerino et al. 1980). Thus, taste-mediated potentiation allows odor to gain associative strength and the animals to avoid consumption of poisonous substance on the basis of its odor only (Bernstein 1991). TPOA learning is an attractive model for studying odor memory because of its robustness, rapid acquisition, and adaptive feature (Welzl et al. 2001).

Most of the data regarding the brain areas that could mediate TPOA learning are provided by either lesion or pharmalogical experiments. Various brains areas involved in olfactory, gustatory, and visceral pain processing could play a role in TPOA learning. Several studies (Bermùdez-Rattoni et al. 1986; Hatfield et al. 1992; Ferry et al. 1995) indicate that the basolateral nucleus of amygdala (BLA) could play a major role in the acquisition but not in the retrieval of TPOA. In addition, the BLA is known for its involvement in learning the biological significance of events and could modulate memory storage of emotional events (McGaugh 2002). In contrast, the lesion of central amygdaloid nucleus (Ce) does not interfere with TPOA learning (Hatfield et al. 1992). As it is one of the main outputs of the BLA, the involvement of the entorhinal cortex (EC) was also studied (Ferry et al. 1996). Its lesion facilitates the acquisition of conditioned odor aversion

\section{'Corresponding author.}

E-mail dardou@cesg.cnrs.fr; fax (33) 3-80-68-16-01.

Article published online ahead of print. Article and publication date are at http://www.learnmem.org/cgi/doi/10.1101/lm.148706
(COA). However, its role in TPOA is not yet established. The EC projects massively to the hippocampus (Hipp), which plays a role in conditioning based on integration of olfactory and gustatory stimuli (Miller et al. 1986). Some frontal areas that have close connections with the BLA (McDonald 1998; Schoenbaum et al. 1999) may also contribute to TPOA. The lesion of the orbitofrontal cortex (VLO) does not modify TPOA acquisition in rats, whereas the one of the anterior insular gustatory cortex impairs both conditioned taste aversion (CTA) and TPOA learning (Lasiter et al. 1985).

It can be noted that until now, most studies focused on the brain areas involved in TPOA acquisition, and little attention was given to the neuronal substrate mediating its retrieval.

The aim of the present study was to investigate the neural network involved in TPOA retrieval. We focused our study on brain regions known to participate in TPOA acquisition: amygdala (Amyg), EC, Hipp, and insular cortex (IC). We further examined the main component of the olfactory cortex, i.e., the piriform cortex (PCx) which is involved in associative olfactory memory (Haberly and Bower 1989; Litaudon et al. 1997; Zinyuk et al. 2001). The infralimbic cortex (IL) was also analyzed as it is connected to the Hipp and receives olfactory inputs via the PCx (Datiche and Cattarelli 1996). Lastly, we examined the possible involvement of the VLO in TPOA retrieval as it receives both olfactory and gustatory inputs (Rolls 2001). To investigate if a differential activation could occur in all these brain areas after TPOA retrieval, immunocytochemical detections of Fos and Egr1 were used.

Fos and Egr1 proteins are inducible transcription factors encoded by the immediate-early genes (IEGs) Fos and Egr1, respectively. These IEGs are activated rapidly and transiently and can be used to map brain activation. In addition, they play a role in neuronal modification underlying memory formation (Herrera and Robertson 1996; Chaudhuri et al. 2000; Guzowski et al. 2001). The Fos protein is critically involved in the formation of AP1 complex that activates the transcription of various late genes, leading to modification of synapse efficacy (Kaczmarek 
2002). Fos brain expression has been used in various learning paradigms, including CTA (Navarro et al. 2000) and olfactory memory (Da Costa et al. 1997; Datiche et al. 2001). Egr1 (Krox24, Egr1, or NGFI-A) is an IEG of the early growth response (Egr) family and might be involved in cerebral plasticity in relation to mnesic processes (Da Costa et al. 1997; Bozon et al. 2002). It plays a role in hippocampal long-term potentiation (Davis et al. 2003). Moreover, differential Egr1 expression was observed in both the Hipp and the Amyg following retrieval of fear memory (Hall et al. 2001). However, no study examined the expression of Egr1 after TPOA retrieval until now. In the experiment reported here, we used Fos and Egr1 immunocytochemistry to map brain activation in rats submitted to either TPOA retrieval (Li-O group) or a sham procedure (Na-O group and $\mathrm{P}-\mathrm{O}$ group).

\section{Results}

\section{Behavioral results}

On the third day after TPOA acquisition, retrieval of TPOA was assessed by a one-bottle test in the presence of the odor. All the animals of the Li-O group showed a decrease in the lick number by $30 \%$ at least, according to the criterion of aversion expression chosen. The ANOVA indicated an effect of the experimental conditions $\left(F_{[3,32]}=12.75, P<0.05\right)$ among the $\mathrm{Li}-\mathrm{O}, \mathrm{Na}-\mathrm{O}$, and $\mathrm{P}-\mathrm{O}$ groups. As illustrated in Figure $1 \mathrm{~A}$, the number of licks in the Li-O, Na-O, and the P-O groups was not significantly different on the TPOA acquisition session. We observed a significant $(P<0.05)$ decrease in the lick number in the Li-O group during the retrieval session compared with the acquisition one. On the contrary, the number of licks was significantly $(P<0.05)$ in-
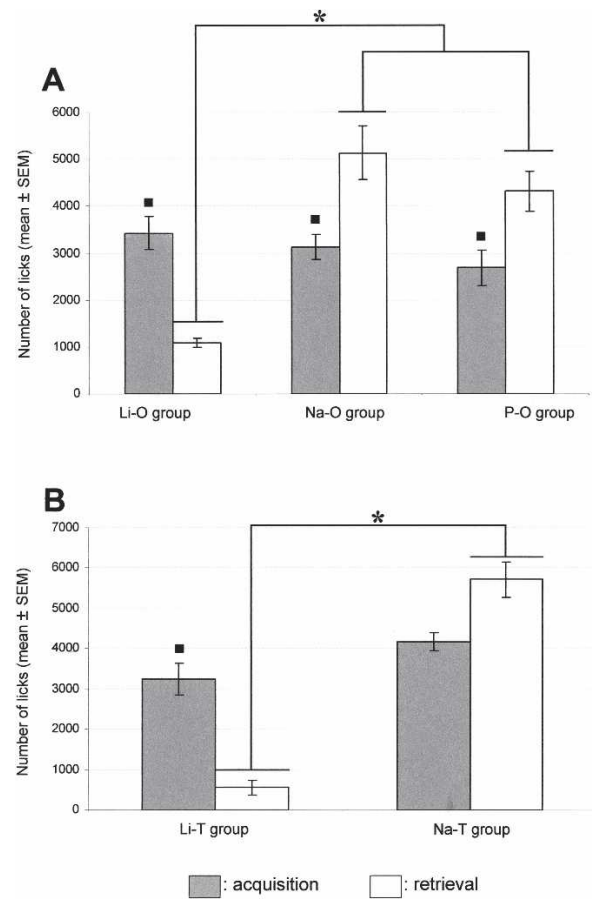

Figure 1. (A) Mean number of licks during the TPOA acquisition session (gray box) and the TPOA retrieval session (white box) in the presence of the odor (geraniol) in the $\mathrm{Li}-\mathrm{O}, \mathrm{Na}-\mathrm{O}$, and $\mathrm{P}-\mathrm{O}$ groups. The square $(\mathbf{\square})$ indicates a significant difference $(P<0.05)$ in the lick number between the acquisition session and the retrieval session. ${ }^{*} P<0.05$. (B) Mean number of licks during the TPOA acquisition session and the TPOA retrieval session in the presence of the taste (saccharin) in the Li-T and $\mathrm{Na}-\mathrm{T}$ groups. The square $(\square)$ indicates a significant difference $(P<0.05)$ in the lick number between the acquisition session and the retrieval session. ${ }^{*} P<0.05$. creased in the $\mathrm{Na}-\mathrm{O}$ and $\mathrm{P}-\mathrm{O}$ groups from the acquisition to the retrieval session. Lastly, during the retrieval session, the lick number was significantly lower $(P<0.05)$ in the Li-O group compared with both the Na-O and P-O groups.

On the third day after TPOA acquisition, the number of licks was counted in the Li-T group and the Na-T one during a onebottle test in presence of the taste alone. These groups were used as behavioral controls in the TPOA procedure since the $\mathrm{LiCl}$ injected rats should also develop a taste aversion. The ANOVA analysis indicated an effect of the experimental conditions $\left(F_{[3,38]}=17.49, P<0.05\right)$ between the Li-T and Na-T groups. The number of licks was significantly decreased in the Li-T group compared with the Na-T group during the retrieval session (Fig. 1B).

The $\mathrm{O}$ group was also used as a behavioral control to ensure that the delay of $30 \mathrm{~min}$ was adequate for the TPOA procedure. The $\mathrm{O}$ group did not exhibit any aversion to the odor cue alone $\left(F_{[4,21]}=1.58, P>0.05\right)$ in our experimental conditions (30-min delay).

\section{Fos and Egrl protein expression}

A general observation can be made about the quantitative Fos and Egr1 protein expression. In all the brain structures analyzed, the number of Egr1-labeled cells was always higher than was the number of Fos-labeled ones (Figs. 2, 3, 4).

\section{Piriform cortex}

In all rats, most labeled cells were localized in layer 2 even if a weak immunostaining was observed in layer 3. ANOVA showed an effect of the experimental conditions on Fos expression in the whole PCx $\left(F_{[3,32]}=79.38 ; P<0.05\right)$. In the PCx and its subdivisions, the Fos expression was significantly $(P<0.05)$ higher in the $\mathrm{Li}-\mathrm{O}, \mathrm{Na}-\mathrm{O}$, and $\mathrm{P}-\mathrm{O}$ rats compared with the $\mathrm{C}$ rats (Fig. $5 \mathrm{~A}$ ). The Li-O and Na-O groups were significantly $(P<0.05)$ more labeled than was the P-O group in the whole PCX and in its anterior $\left(F_{[3,32]}=58.38 ; P<0.05\right)$ and posterior $\left(F_{[3,32]}=77.76 ; P<0.05\right)$ parts. Moreover, in the $\mathrm{Li}-\mathrm{O}, \mathrm{Na}-\mathrm{O}$, and $\mathrm{P}-\mathrm{O}$ groups, the number of Fos-labeled cells was significantly higher in the PCX-a compared with the PCx-p $\left(F_{[3,65]}=79.09 ; P<0.05\right)$.

In the whole PCx, Egr1 expression was twice larger than was the Fos expression whatever the group of rats (Fig. 5B). The ANOVA indicated an effect of the experimental conditions on Egr1 expression in the whole PCx $\left(F_{[3,32]}=79.38 ; P<0.05\right)$, in the PCX-a $\left(F_{[3,29]}=139.81 ; P<0.05\right)$, and in the PCX-p $\left(F_{[3,29]}=142.10 ; P<0.05\right)$. Pairwise comparisons showed that the $\mathrm{C}$ group was significantly $(P<0.05)$ less labeled than were the Li-O and Na-O groups. No significant difference was found between the $\mathrm{P}-\mathrm{O}$ and $\mathrm{C}$ groups. In both the whole $\mathrm{PCx}$ and its subdivisions, the Li-O and $\mathrm{Na}-\mathrm{O}$ groups were significantly $(P<0.05)$ more labeled than was the P-O group. We observed that the number of Egr1-positive cells was significantly $(P<0.05)$ higher in the Li-O group compared with the Na-O group in the whole PCx and in the PCx-a. Egr1 immunoreactivity in the Li-O, Na-O, and P-O groups was significantly increased in the PCx-a compared with the PCX-p $\left(F_{[3,59]}=209.74 ; P<0.05\right)$.

\section{Hippocampus}

In the dorsal Hipp, we noted an effect of the experimental conditions on Fos expression in CA1 $\left(F_{[3,26]}=80.20 ; P<0.05\right)$, in CA3 $\left(F_{[3,26]}=23.79 ; P<0.05\right)$, and in the dentate gyrus (DG; $\left.F_{[3,26]}=46.43 ; P<0.05\right)$. Whatever the hippocampal subfield, the number of Fos-labeled cells was significantly $(P<0.05)$ larger in the $\mathrm{Li}-\mathrm{O}, \mathrm{Na}-\mathrm{O}$, and $\mathrm{P}-\mathrm{O}$ groups than in the $\mathrm{C}$ one. In the CA1 and CA3 subfields, the Li-O group showed a significantly $(P<0.05)$ higher Fos immunoreactivity (Fig. $5 C)(P<0.05)$ than did the Na-O and $\mathrm{P}-\mathrm{O}$ groups. In the $\mathrm{DG}$, the $\mathrm{Na}-\mathrm{O}$ group was 


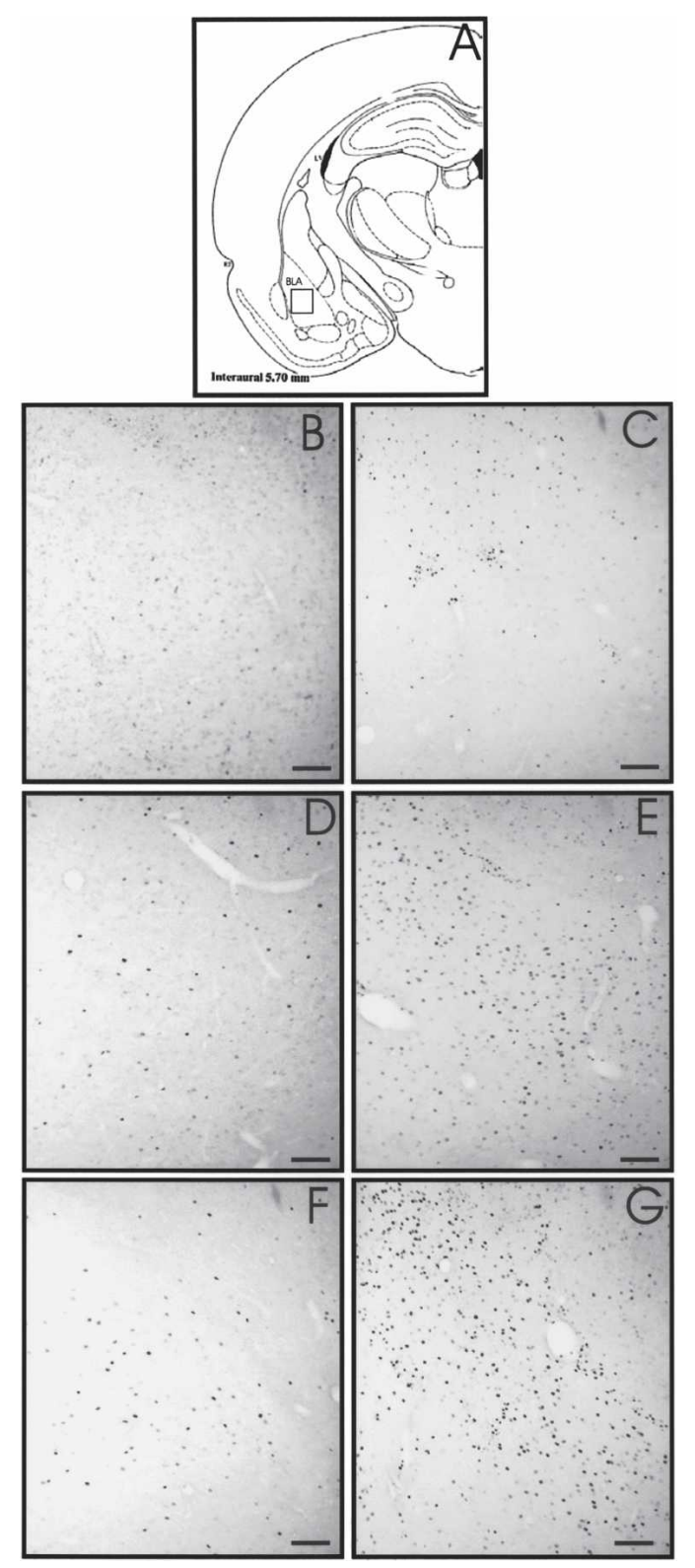

Figure 2. Fos and Egr1 protein expression in the BLA. Schematic section $(A)$ reprinted with permission from Elsevier (C) 1986, Paxinos and Watson (1986). The square window indicates the area shown in the photomicrographs. Photomicrographs $B, D$, and $F$ of Fos expression in $C$, $\mathrm{Na}-\mathrm{O}$, and Li-O rats, respectively. $(C, E, G)$ Illustrations of Egr1-labeled cells in $\mathrm{C}, \mathrm{Na}-\mathrm{O}$, and Li-O rats, respectively. Horizontal bar, $100 \mu \mathrm{m}$.

significantly $(P<0.05)$ more labeled than were the Li-O and $\mathrm{P}-\mathrm{O}$ groups.

In the ventral Hipp, the ANOVA analysis showed that the experimental conditions had a significant effect on Fos expression in both CA1 $\left(F_{[3,23]}=17.91 ; P<0.05\right)$ and $\mathrm{CA} 3$ $\left(F_{[3,23]}=34.66 ; P<0.05\right)$. The Fos expression was significantly $(P<0.05)$ lower in the $\mathrm{C}$ group in comparison with the three other ones. In CA1 and CA3, the number of Fos-labeled cells was significantly higher in the Li-O rats compared with the Na-O and P-O rats (Fig. 5E).

In the dorsal Hipp, the ANOVA analysis indicated that experimental conditions had a significant effect on Egr1 expression in CA1 $\left(F_{[3,23]}=109.85 ; P<0.05\right)$, CA3 $\left(F_{[3,23]}=327.90 ; P<0.05\right)$ and DG $\left(F_{[3,23]}=77.77 ; P<0.05\right)$. In these three hippocampal subfields, Egr1 immunoreactivity was significantly $(P<0.05)$ lower in the $\mathrm{C}$ group compared with the $\mathrm{Li}-\mathrm{O}$ and $\mathrm{Na}-\mathrm{O}$ groups. Egr1 immunoreactivity in the P-O rats was significantly different compared with the $\mathrm{C}$ rats only in the CA3 hippocampal subfield. In both CA1 and CA3 subfields, Egr1 expression (Fig. 5D) was significantly higher in the Li-O group than in the Na-O one $(P<0.05)$. In the DG, no significant difference between the $\mathrm{Li}-\mathrm{O}$ and Na-O groups was observed. In all the hippocampal subfields, the Li-O and Na-O groups were significantly $(P<0.05)$ more labeled than was the P-O one.

In the ventral Hipp, the ANOVA indicated that the experimental conditions had a significant effect on Egr1 expression in the CA1 $\left(F_{[3,17]}=14.41 ; P<0.05\right)$ and CA3 $\left(F_{[3,17]}=7.91\right.$; $P<0.05$ ) subfields (Fig. 5F). The Li-O and Na-O rats were significantly more labeled than were the $\mathrm{C}$ rats. However, no significant difference was noted between the $\mathrm{P}-\mathrm{O}$ and $\mathrm{C}$ rats. In both these subfields, the Li-O and Na-O groups showed significantly $(P<0.05)$ more Egr1-positive cells than did the P-O group.

\section{Amygdala}

In the Amyg, we noted an effect of the experimental conditions on Fos protein expression in the BLA $\left(F_{[3,27]}=59.68 ; P<0.05\right)$ and in the Ce $\left(F_{[3,28]}=11.60 ; P<0.05\right)$. In both the BLA and the $\mathrm{Ce}$, the Li-O, Na-O, and $\mathrm{P}-\mathrm{O}$ groups were significantly $(P<0.05)$ more labeled than was the $\mathrm{C}$ one (Fig. $2 \mathrm{~B}, \mathrm{D}, \mathrm{F})$. In the BLA, Fos immunoreactivity (Fig. 5G) was significantly $(P<0.05)$ increased in the $\mathrm{Li}-\mathrm{O}$ group compared with the $\mathrm{Na}-\mathrm{O}$ and $\mathrm{P}-\mathrm{O}$ groups. In the Ce we also observed a significant $(P<0.05)$ increase in the number of Fos-labeled cells in the Na-O group compared with the $\mathrm{P}-\mathrm{O}$ group.

Statistical analysis indicated an effect of the experimental conditions on Egr1 expression in the BLA $\left(F_{[3,21]}\right]=34.04$; $P<0.05)$ and in the Ce $\left(F_{[3,21]}=4.98 ; P<0.05\right)$ (Fig. 5H). In both the BLA and the Ce, Egr1 immunoreactivity was significantly $(P<0.05)$ lower in the $\mathrm{C}$ group compared with the Li-O and Na-O groups (Fig. 2C,E,G). No difference was found between the P-O and $\mathrm{C}$ rats. In the BLA, Egr1 expression was significantly $(P<0.05)$ higher in the Li-O group compared with the Na-O group. In addition, the $\mathrm{P}-\mathrm{O}$ group was significantly $(P<0.05)$ less labeled than were the $\mathrm{Li}-\mathrm{O}$ and $\mathrm{Na}-\mathrm{O}$ groups. In the Ce, Egr1 expression was significantly $(P<0.05)$ higher in the Li-O group than in the Na-O and $\mathrm{P}-\mathrm{O}$ ones, but no significant difference was found between the Na-O and P-O groups.

\section{Entorhinal cortex}

ANOVA indicated that experimental conditions had an effect on both Fos and Egr1 expressions $\left(F_{[3,31]}=17.63 ; P<0.05\right.$ and $F_{[3,28]}=53.06 ; P<0.05$ respectively) (Fig. $6 \mathrm{~A}$ ). Fos immunoreactivity was significantly $(P<0.05)$ lower in the $\mathrm{C}$ group compared with the Li-O and Na-O groups (Fig. 3A1,2). However no difference was found between the $\mathrm{P}-\mathrm{O}$ and $\mathrm{C}$ groups. The number of Fos-labeled cells was significantly $(P<0.05)$ higher in the Na-O group compared with the $\mathrm{Li}-\mathrm{O}$ and $\mathrm{P}-\mathrm{O}$ groups.

Egr1 expression was significantly $(P<0.05)$ lower in the $\mathrm{C}$ group (Fig. 3A3,4) compared with the Li-O, Na-O, and P-O groups. The Li-O group exhibited significantly $(P<0.05)$ more Egr1-labeled cells (Fig. 6B) than did the Na-O and P-O groups. We also noted that Egr1 protein expression was significantly $(P<0.05)$ higher in the Na-O group compared with the $\mathrm{P}-\mathrm{O}$ group.

\section{Orbito-frontal cortex}

An effect of the experimental conditions was observed in the VLO for both Fos $\left(F_{[3,32]}=13.28 ; P<0.05\right)$ and Egr1 $\left(F_{[3,29]}=47.47 ; P<0.05\right)$ expression (Fig. 3B). The number of either Fos- or Egr1-labeled cells was significantly $(P<0.05)$ lower in

\section{Learning \& Memory}

www.learnmem.org 

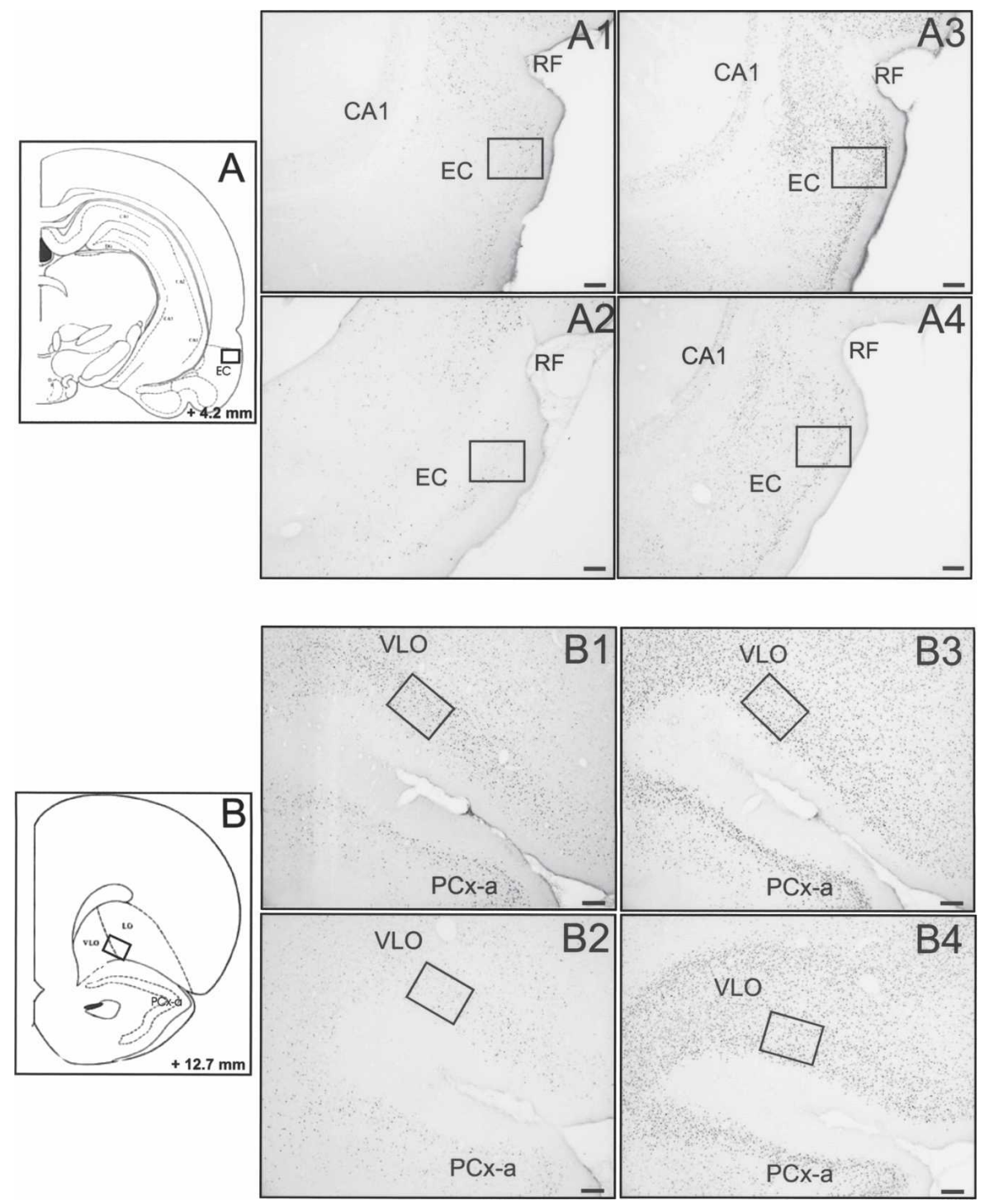

Figure 3. Fos and Egr1 protein expression after TPOA retrieval in the EC and VLO. Schematic sections reprinted with permission from Elsevier (C) 1986, Paxinos and Watson (1986) showing the location of the counting windows (size, $0.15 \mathrm{~mm}^{2}$ ) in the $\mathrm{EC}(A)$ and in the VLO $(B)$. Photomicrographs of the EC illustrating Fos immunoreactivity in the Li-O and the $\mathrm{C}$ groups ( $A 1$ and $A 2$, respectively) and Egr1 immunoreactivity in the $\mathrm{Li}-\mathrm{O}$ and the $\mathrm{C}$ groups ( $A 3$ and $A 4$, respectively). Photomicrographs of the VLO showing Fos expression in the $\mathrm{Li}-\mathrm{O}(B 1)$ and $C(B 2)$ groups and Egr1 expression in the Li-O (B3) and $C(B 4)$ groups. Horizontal bar, $100 \mu \mathrm{m}$. LO, lateral orbitofrontal cortex; and RF, rhinal fissure.

the $\mathrm{C}$ rats compared with the $\mathrm{Li}-\mathrm{O}, \mathrm{Na}-\mathrm{O}$, and $\mathrm{P}-\mathrm{O}$ rats. Fos immunoreactivity was not significantly different in the Li-O group compared with the Na-O group (Fig. 6C). However, the number of Fos-positive cells was significantly $(P<0.05)$ larger in the Li-O group than the P-O one.

No difference was noted in Egr1 expression among the Li-O, Na-O, and P-O groups (Fig. 6D).

\section{Infralimbic cortex}

Experimental conditions had a significant effect on the expression of Fos $\left(F_{[3,30]}=68.25 ; P<0.05\right)$ and Egr1 $\left(F_{[3,28]}=12.99\right.$; $P<0.05$ ) (Fig. 4A). Fos immunoreactivity was significantly $(P<0.05)$ lower in the $\mathrm{C}$ group than in the Li-O, Na-O, and $\mathrm{P}-\mathrm{O}$ groups. The Na-O group showed a significant $(P<0.05)$ increase in Fos expression in comparison with the $\mathrm{Li}-\mathrm{O}$ and $\mathrm{P}-\mathrm{O}$ groups (Fig. 6E).
Egr1 immunoreactivity was significantly $(P<0.05)$ lower in the $\mathrm{C}$ group compared with the $\mathrm{Li}-\mathrm{O}$ and the Na-O groups (Fig. 6F). However, no significant difference was observed between the $\mathrm{P}-\mathrm{O}$ and $\mathrm{C}$ groups, on one hand, and between the Li-O and Na-O groups, on the other hand. The numbers of Egr1positive cells was significantly $(P<0.05)$ lower in the $\mathrm{P}-\mathrm{O}$ group compared with the $\mathrm{Li}-\mathrm{O}$ and $\mathrm{Na}-\mathrm{O}$ groups (Fig. 4A3,4).

\section{Insular cortex}

There was an effect of experimental conditions on Fos $\left(F_{[3,31]}=80.76 ; P<0.05\right)$ and Egr1 $\left(F_{[3,28]}=21.87 ; P<0.05\right)$ protein expression. Fos (Fig. 4B1-3) and Egr1 (Fig. 4B4-6) immunoreactivities were significantly $(P<0.05)$ larger in the $\mathrm{Li}-\mathrm{O}, \mathrm{Na}-\mathrm{O}$, and $\mathrm{P}-\mathrm{O}$ groups than in the $\mathrm{C}$ group. Expression of both Fos and Egr1 proteins was significantly increased in the Li-O rats compared with the $\mathrm{Na}-\mathrm{O}$ and $\mathrm{P}-\mathrm{O}$ rats (Fig. 6G,H). Fos expression was increased in the Na-O group compared with the P-O group, whereas no difference in Egr1 expression was found between these groups.

\section{Discussion}

The present study examined the neuronal substrate involved in TPOA retrieval. Rats acquired TPOA by simultaneous presentation of geraniol and saccharin followed by $\mathrm{LiCl}$ delayed-illness. On the third day after acquisition, they were stimulated by geraniol in order to reactivate TPOA memory. Immunocytochemical detection of both Fos and Egr 1 proteins was used to map the cerebral regions activated by the geraniol odor, which acquired an aversive significance through taste potentiation.

Behavioral data showed that rats receiving $\mathrm{LiCl}$ injection $30 \mathrm{~min}$ after odor and taste presentation developed TPOA. The number of licks was significantly decreased during the retrieval elicited by presentation of the geraniol odor cue. We also observed that rats exhibited an aversive behavior toward the taste cue. Most studies about the TPOA phenomenon have used benzaldehyde as the odor cue (Palmerino et al. 1980; Bernstein 1991; Batsell Jr. and Batson 1999). Thus according to the present data, TPOA can be elicited by various odor cues. On the contrary, neither the Na-O nor the $\mathrm{P}-\mathrm{O}$ rats showed an aversion toward the odor cue.

In accordance with previous data (Datiche et al. 2001), Fos immunoreactivity in the home-cage $\mathrm{C}$ group was very low. In all the brain areas except the EC, the expression of Fos was significantly lower in the $\mathrm{C}$ rats compared with the Li-O, Na-O, and $\mathrm{P}$ rats.

We observed a constitutive expression of Egr1 in the cortical and limbic brain areas in the $\mathrm{C}$ group, as reported by Davis et al. (2003). In all the brain areas, the expression of Egr1 was significantly lower in the $\mathrm{C}$ group compared with both $\mathrm{Li}-\mathrm{O}$ and $\mathrm{Na}-\mathrm{O}$ groups. 

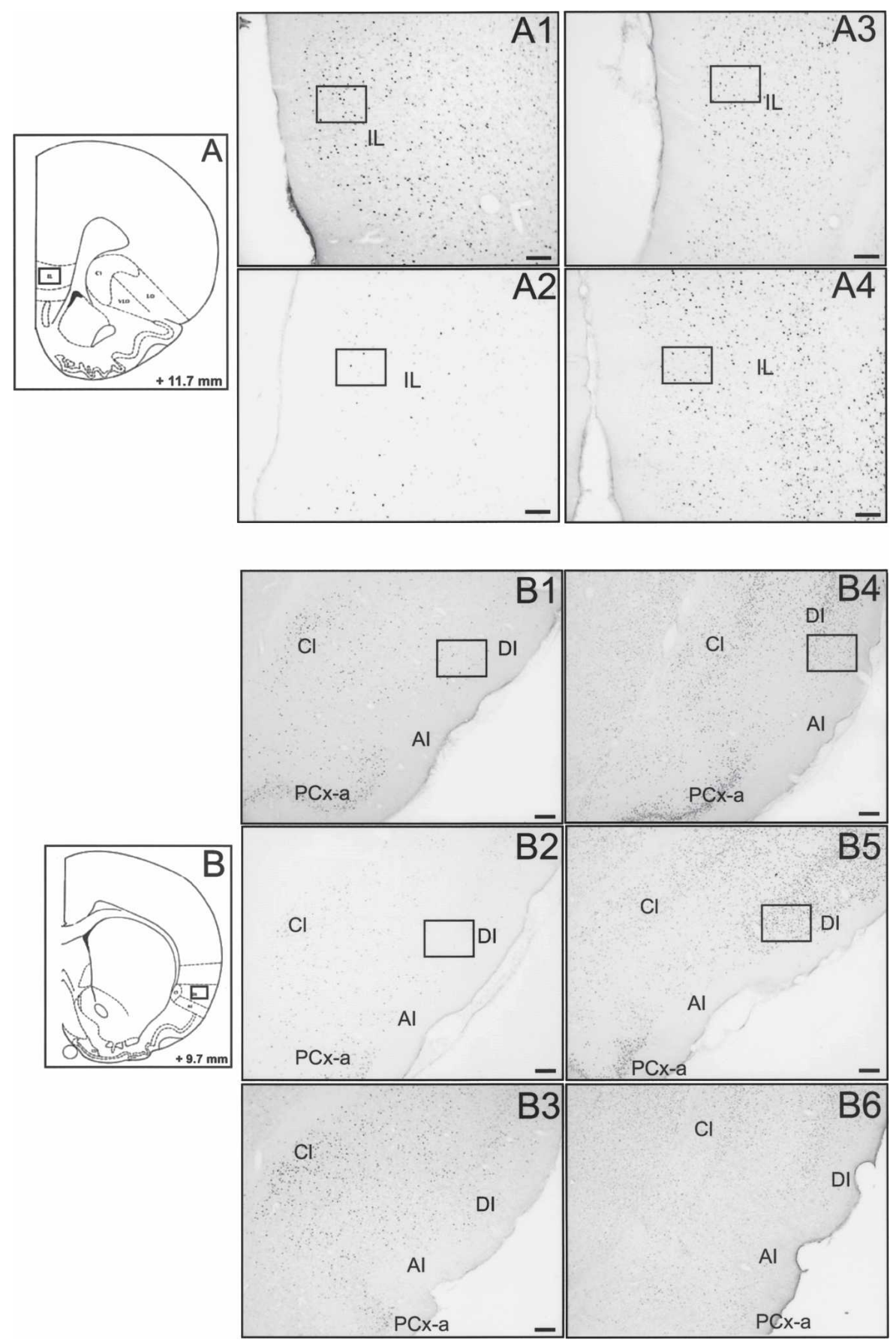

Figure 4. Fos and Egr1 protein expression after TPOA retrieval in the IL and IC. Schematic sections reprinted with permission from Elsevier (C) 1986, Paxinos and Watson (1986) showing the location of the counting window (size, $0.15 \mathrm{~mm}^{2}$ ) in the IL $(A)$ and the IC $(B)$. Photomicrographs of the IL $(A)$ illustrating Fos and Egr1 immunoreactivities in the $\mathrm{Li}-\mathrm{O}$ ( $A 1$ and $A 3$, respectively) and the $\mathrm{C}$ rats ( $A 2$ and $A 4$, respectively). Photomicrographs of the IC $(B)$ showing Fos and Egr1 immunoreactivities in the Li-O ( $B 1$ and $B 4$, respectively), in the $C$ ( $B 2$ and $B 5$, respectively) and in the $\mathrm{P}-\mathrm{O}$ groups ( $B 3$ and $B 6$, respectively). Horizontal bar, $100 \mu \mathrm{m}$. Al indicates agranular part of insular cortex; $\mathrm{Cl}$, claustrum; DI, dysgranular part of insular cortex; and LO, lateral orbitofrontal cortex.

However, in the PCx, CA1, DG, ventral Hipp, BLA, Ce, and IL areas, the expression of Egr1 in the $\mathrm{C}$ rats was not different in comparison with the P rats.

In the experiment reported here, two groups of control rats were carried out in order to examine either the effect of paired injection without visceral illness (Na-O group) or the effect of unpaired injection of $\mathrm{LiCl}$ inducing visceral illness without association with the odor and taste stimulations (P-O group) on Fos and Egr1 expressions. The use of these two control groups is of interest since it is well known that the IEGs Fos and Egr1 are activated by multiple signaling pathways and that Fos protein expression can be driven by a number of different stimuli and conditions (Herrera and Robertson, 1996). Previously, we highlighted the crucial importance of the choice of controls in experiments using Fos immunocytochemistry (Roullet et al. 2005). Even if the $\mathrm{Na}-\mathrm{O}$ and the $\mathrm{P}-\mathrm{O}$ groups did not exhibit any odor aversion, it is noticeable that Fos and Egr1 expressions were not identical in these two groups. Rats that received $\mathrm{NaCl}$ injection after being submitted to both odor and taste cues are usually considered as adequate controls since they do not develop TPOA (Ferry et al. 1995). However, as $\mathrm{LiCl}$ elicits visceral illness, the $\mathrm{P}-\mathrm{O}$ rats were also used in this experiment in order to test if $\mathrm{LiCl}$ might induce long-term modifications of Fos and Egr1 expression, which could account for the data obtained in the Li-O group. Thus, the $\mathrm{P}-\mathrm{O}$ rats received a paired $\mathrm{NaCl}$ injection $30 \mathrm{~min}$ after simultaneous presentation of both odor and taste cues and an unpaired $\mathrm{LiCl}$ injection $24 \mathrm{~h}$ later. In all the brain regions analyzed, the expression of both Egr1 and Fos in the $\mathrm{P}-\mathrm{O}$ rats was either lower or similar to that observed in the Na-O rats. Thus, in our experimental conditions, it seems that the odor stimulation did not exert a similar effect on Fos and Egr1 induction in the $\mathrm{Na}-\mathrm{O}$ and $\mathrm{P}-\mathrm{O}$ rats. One possible explanation could be that the $P$ rats received two intraperineal injections, one of $\mathrm{NaCl}$ and an additional injection of illness-inducing LiCl. However, Spencer and Houpt (2001), who examined the time-course of Fos in rat forebrain following $\mathrm{LiCl}$ administration, showed a return of Fos mRNA to baseline about $9 \mathrm{~h}$ after the injection, indicating that $\mathrm{LiCl}$ had a rather limited effect on Fos expression. In our paradigm, the P-O rats were sacrificed $2 \mathrm{~d}$ after the $\mathrm{LiCl}$ injection. Thus, the decrease in Fos and Egr1 labeling observed in the $\mathrm{P}-\mathrm{O}$ rats compared with the $\mathrm{Na}-\mathrm{O}$ rats in our experiment seems not a result from a prolonged effect of the illness induced by the $\mathrm{LiCl}$ injection. Moreover, the data reported here showed that the expression of Fos and Egr1 in the Li-O rats was always significantly larger than those observed in the P-O rats. Such a finding underlines that the neuronal activation observed in the $\mathrm{LiCl}$-aversive rats should not depend on the sole illness but should rather reflect mnesic processes linked to conditioned stimulus-unconditioned stimulus (CS-US) association. 


\section{L.0 $\square$ Na. $0.0 \square$ C $\square$ \\ - C different from Na-O and Li-O Groups. \\ - C different from the Li-O, Na-O and P-O groups. \\ \& $\mathbf{P}$ group different from the $\mathrm{Li}-\mathrm{O}$ and $\mathrm{Na}-\mathrm{O}$ groups.}

Piriform cortex
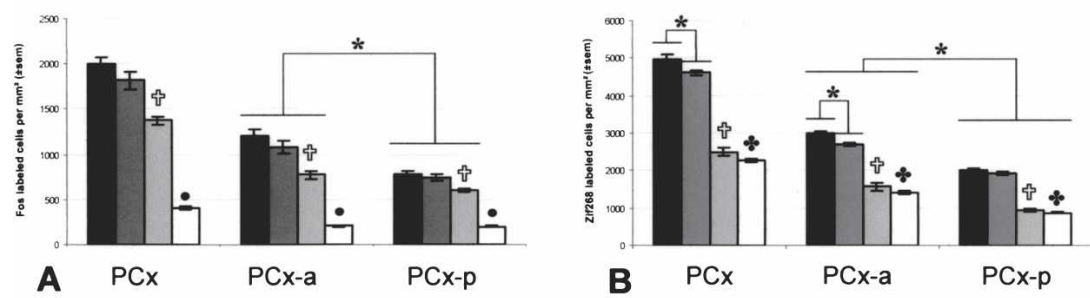

Dorsal Hippocampus

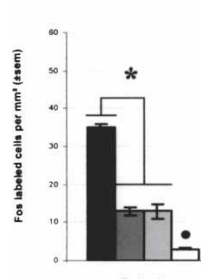

C

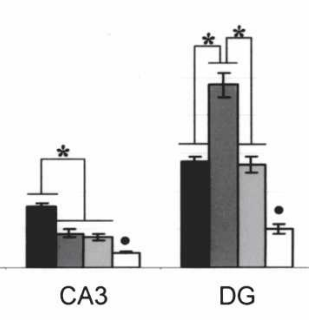

Ventral Hippocampus

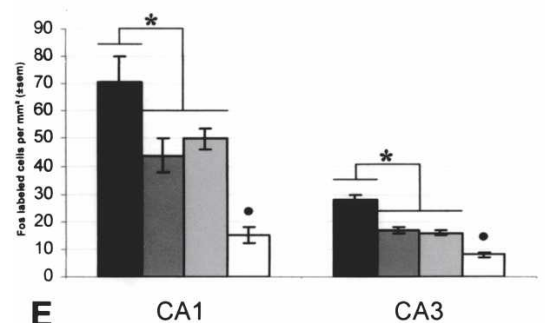

$\mathbf{E}$

CA1

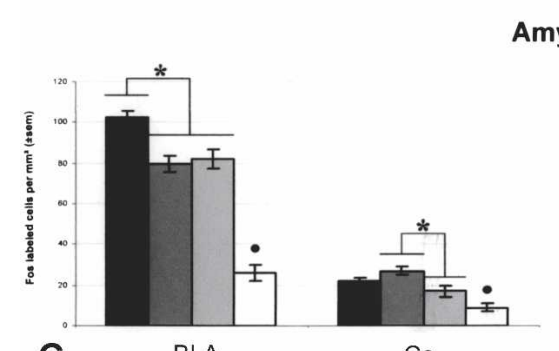

G

$\mathrm{BI} \mathrm{A}$

$\mathrm{Ce}$
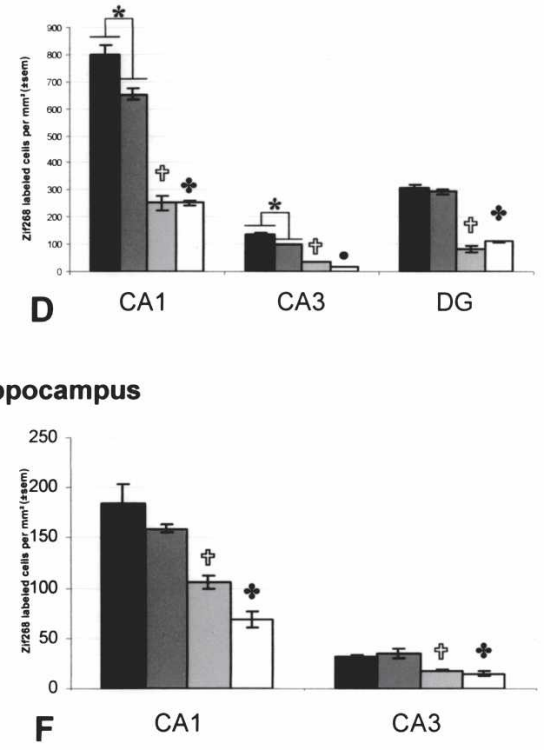

Amygdala

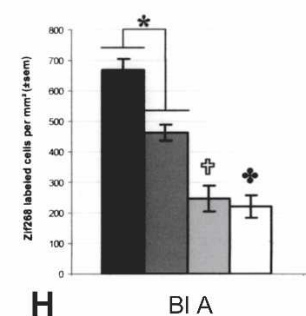

H

BI A

Figure 5. Mean numbers of Fos- and Egr1-positive cells (left and right panels, respectively) in the PCX $(A, B)$, the dorsal $(C, D)$, and ventral $(E, F)$ hippocampal subfields, the BLA and the Ce nuclei $(G, H)$. *Data significantly different at $P<0.05$.

Except the LiCl-induced illness, another feature could account for the difference in IEG expression between the P-O and $\mathrm{Na}-\mathrm{O}$ control rats. To have a similar delay between the LiClinduced illness and the retrieval test day in the P-O and Li-O groups, two resting days separated the $\mathrm{LiCl}$ injection from the odor presentation in the $\mathrm{P}-\mathrm{O}$ rats. Consequently, the Na-O rats and the P-O rats were sacrificed 2 and $3 \mathrm{~d}$ after the initial simultaneous presentation of both odor and taste cues, respectively. It can be hypothesized that this difference in the delay could account for the lower immunoreactivity in the P-O rats. As an additional day separated the initial stimulation from the test session, a differential odor processing, in terms of familiarity, might

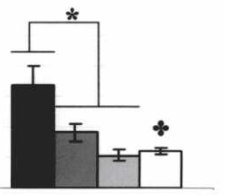

$\mathrm{Ce}$ occur in some brain areas. Lastly, even if the LiCl by itself should not still exert an effect on Fos expression since rats were sacrificed $2 \mathrm{~d}$ later, it remains that such an injection is a stressful event, which might nevertheless modify neuronal activity in some cerebral regions. In rats, a repeated stress has been shown to induce a decrease in Fos and Egr1 mRNA expressions compared with an acute stress (Melia et al. 1994). In our protocol, the intraperineal injection could represent an acute stress for the Li-O and the $\mathrm{Na}-\mathrm{O}$ rats, which were submitted to only one injection of $\mathrm{LiCl}$ or $\mathrm{NaCl}$. On the contrary, the $\mathrm{P}-\mathrm{O}$ rats received two successive injections, one of paired $\mathrm{NaCl}$ and, on the day after, one of unpaired $\mathrm{LiCl}$, which might represent a repeated stress for the rat and consequently could induce a decrease in both Fos and Egr1 expressions in some of the brain areas considered. Thus, it seems reasonable to consider that the Na-O control rats can be compared to the Li-O rats as both these groups were tested in similar timedelay and similar stress conditions.

The Fos expression in the Hipp (except DG), the BLA, and the IC was significantly higher in the Li-O rats compared with the Na-O rats. Conversely, in the $\mathrm{EC}$ and the IL, the Fos immunoreactivity was significantly lower in the Li-O rats compared with the $\mathrm{Na}-\mathrm{O}$ rats. In the $\mathrm{Ce}$, no significant difference was found between the $\mathrm{Li}-\mathrm{O}$ and the $\mathrm{Na}-\mathrm{O}$ rats.

Water deprivation is known to increase Fos immunoreactivity in brain areas involved in osmolality and in volemia (Morien et al. 1999). As we focused our analysis on olfactory-related brain areas, such an influence should remain low. Nevertheless, it cannot be totally put aside, especially at the neocortical level, where integration of various information takes place.

Egr1 expression in the Li-O rats was higher or at least equal to that observed in the Na-O rats in all the brain areas examined. It was significant in the whole PCx, the PCx-a, the dorsal Hipp, the BLA, the Ce, the EC, and the IC. Egr1 has been shown to be a useful marker to map brain areas involved in olfactory memory (Da Costa et al. 1997). Our data further indicate a regional expression of Egr1 related to TPOA retrieval.

In the whole PCx and its subdivisions, no significant change in Fos expression was found between the $\mathrm{Li}-\mathrm{O}$ and $\mathrm{Na}-\mathrm{O}$ groups. Egr1 immunoreactivity was significantly higher only in the PCX and the PCx-a of the Li-O group compared with the Na-O group, but such difference remained slight. Several studies using an electrophysiological approach (Roman et al. 1987; Litaudon and Cattarelli 1996; Litaudon et al. 1997; Mouly and Gervais 2002) suggest a role of this cortex in olfactory memory. However, the involvement of PCx in aversive conditioning has received little attention until now. The present data show a limited activation 


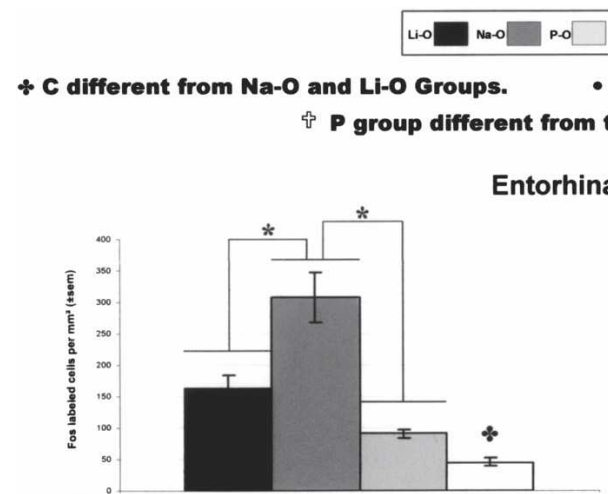

A

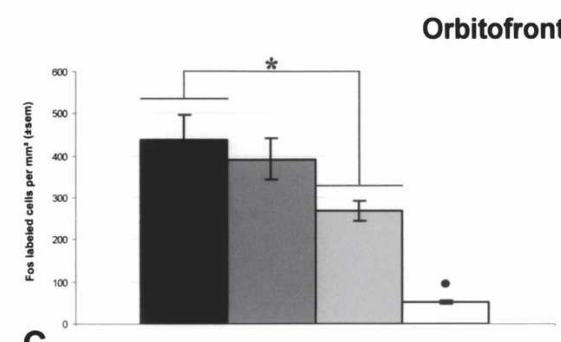

C

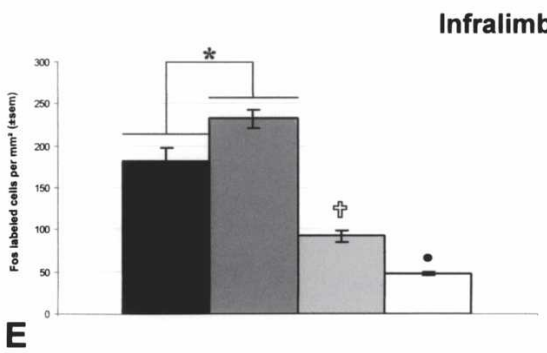

- C different from the Li-O, Na-O and P-O groups.

the Li-O and Na-O groups.

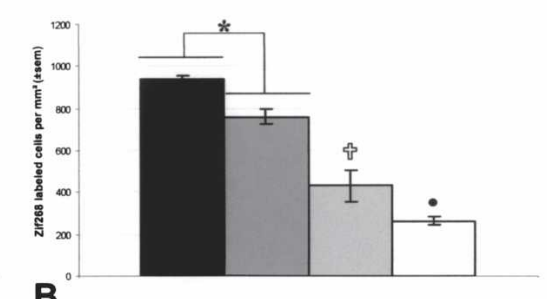

B

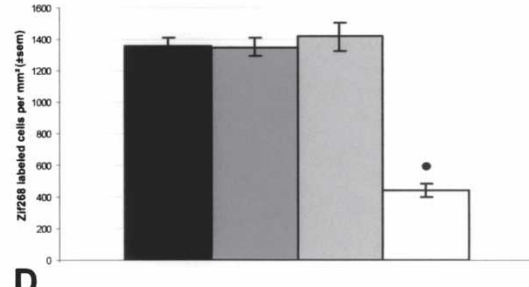

D

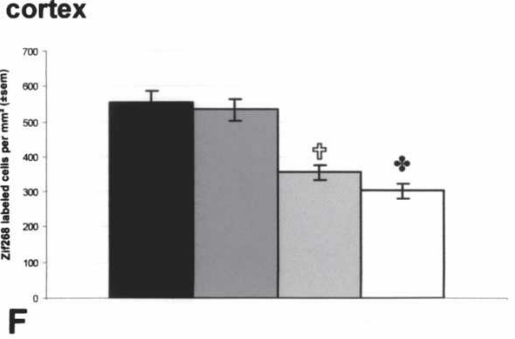

Insular cortex
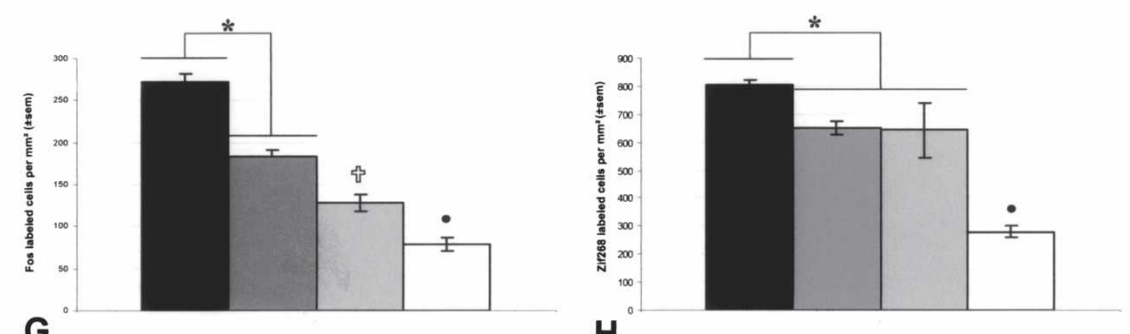

H

Figure 6. Mean numbers of Fos- and Egr1-positive cells (left and right panels, respectively) in the entorhinal $(A, B)$, orbitofrontal $(C, D)$, infralimbic $(E, F)$, and insular $(G, H)$ cortices. *Data significantly different at $P<0.05$.

of the PCx when rats are stimulated by the odor that acquired an aversive value. As the PCx receives dense bulbar inputs, it cannot be ruled out that the activity elicited by olfactory stimulation could have masked the mnesic-related one. In both Li-O and Na-O groups, Fos and Egr1 immunoreactivities were significantly higher in the PCx-a compared with the PCx-p. This result is in accordance with previous observations (Datiche et al. 2001). The anteroposterior decrease in labeling could reflect the distribution of bulbar inputs to the $\mathrm{PCx}$, which are known to be more numerous rostrally.

Our data bring new insights regarding the role of the Hipp in processing an odor cue predicting an aversive outcome. In the dorsal Hipp (CA1 and CA3), the expression of Fos and Egr1 was significantly higher in the Li-O group compared with the Na-O group. In the ventral Hipp (CA1 and CA3), the expression of Fos was increased in the Li-O rats compared to the Na-O rats, whereas no modification in Egr1 immunoreactivity was noted. Hipp is known to play a crucial role in olfactory memory (Hess et al. 1995; Eichenbaum 1998). Nevertheless, only a few studies reported a hippocampal involvement in encoding odor cues in aversive learning. Lesions of the dorsal Hipp have been shown to disrupt the acquisition of a COA as well as neophobic responses to a novel odor cue (Miller et al. 1986). Moreover, cholinergic activity of the Hipp might modulate TPOA retrieval and COA learning (BermùdezRattoni et al. 1987). Hippocampal involvement in TPOA retrieval might also be related to its role as an associator of discontiguous events (Wallenstein et al. 1998). Lastly, functional interactions between the ventral Hipp and the Amyg might also sustain memory of aversive events (Alvarez and Ruarte 2004).

In the BLA nucleus of the Amyg, we provided evidence that TPOA retrieval elicited significantly higher Fos and Egr1 immunoreactivities in the $\mathrm{Li}-\mathrm{O}$ rats compared with the Na-O rats. The BLA seems to be involved in olfactory discrimination learning (Hess et al. 1997). Moreover, the Amyg is essential in aversive and emotional learning (Cardinal et al. 2002; Mc Gaugh 2002), and plays a role in fear conditioning retrieval (Nader et al. 2000; Hall et al. 2001). However, BLA electrolytic or pharmacological lesions impaired TPOA acquisition but not its retrieval. Such an effect seemed rather selective since CTA acquisition was not disturbed in these rats (Hatfield et al. 1992; Ferry et al. 1995). The discrepancy between these results and the present data indicating an involvement of the BLA in TPOA retrieval could result from the methods used, i.e., lesions versus IEG mapping.

The Ce nucleus of the Amyg exhibited a significantly higher Egr1 expression in the Li-O rats in comparison with the $\mathrm{Na}-\mathrm{O}$ rats. The Ce might be involved in the integration of visceral pain sustaining emotional memories formation (Tanimoto et al. 2003) and, subsequently, might act as a brainstem controller in some behavioral, autonomic, and neuroendocrine responses (Cardinal et al. 2002). Furthermore, the Ce could play a role in the formation of a gustatory memory trace since inhibition of protein synthesis within this nucleus during training blocks CTA learning (Lamprecht et al. 1997). However, it is not yet well established whether the Ce is also involved in TPOA. Hatfield et al. (1992) did not observe any impairment in TPOA acquisition after excitotoxic lesion of the Ce. However, the Egr1 expression pattern observed here suggests a possible role of this nucleus in TPOA retrieval that could be related to its anatomical and functional links with BLA (McDonald 1998). 
In the EC, Egr1 immunoreactivity was significantly higher in the Li-O group compared with the Na-O group, whereas it was the reverse for Fos expression. A differential induction of IEGs was already reported in a spatial learning task (Guzowski et al. 2001). It can also be underlined that opposite expression levels of these two proteins were described in the visual system (Yamada et al. 1999). Expression of either Fos or Egr1 might be regulated through distinct pathways that affect activity-dependent synaptic plasticity. Such a differential regulation could be based on Cand A- protein kinase dependent pathways, which might differently contribute to dopaminergic induction of Fos and Egr1 gene expression, respectively (Simpson and Morris 1995). The EC receives olfactory inputs from the olfactory bulb and the PCx. Its role in olfactory learning seems to be complex (Kaut et al. 2003), and the internal nutritional state could differentially modulate odor processing in this cortical area (Chabaud et al. 2000). Lesion of the EC facilitates COA learning by prolonging the olfactory trace duration and renders it tolerant to extended interstimulus interval (Ferry et al. 1996). Our present data suggest a role of the EC in TPOA expression. Nevertheless, additional investigations will be necessary to elucidate the differential expression of both markers in the $\mathrm{Li}-\mathrm{O}$ and Na-O rats in the EC. It can be hypothesized that the obvious opposite expression patterns of Fos and Egr1 could reflect a different temporal involvement of these markers when TPOA retrieval occurs.

In the VLO, no significant change in either Fos or Egr1 expression was observed between the Na-O and Li-O groups. The VLO is well known as a site of convergence of both odor and taste cues (Rolls 2001). This area has also reciprocal connections with the BLA and might cooperate with this nucleus to process odor cues that have an aversive outcome. However, our data show that the neuronal activation in VLO seems primarily in relation with odor processing only. The lack of difference between the $\mathrm{Li}-\mathrm{O}$ and Na-O groups is in accordance with the study of Lasiter et al. (1985) showing a minor involvement of this area in TPOA acquisition. The role of the VLO in aversive conditioning could depend on the learning paradigm. Lastly, it cannot be ruled out that an activation of the VLO might occur at different timewindows, e.g., if TPOA memory would be recalled after several days of retention.

The Fos immunoreactivity in the IL was significantly lower in the Li-O rats compared with $\mathrm{Na}-\mathrm{O}$ rats. This infralimbic region of the medial frontal cortex is connected to the PCx (Datiche and Cattarelli 1996) and to the nucleus of the solitary tract. The IL is believed to integrate viscerosensory inputs (Sesack et al. 1989). It could be hypothesized that the IL might more likely be involved in processing visceral cues during TPOA acquisition.

In the IC, we provided evidence that the expression of both Fos and Egr1 after TPOA retrieval was significantly higher in the Li-O group compared with the Na-O group. The IC receives gustatory inputs (Nakashima et al. 2000) as well as indirect olfactory inputs via its connections with the PCx (Datiche and Cattarelli 1996). According to Kiefer et al. (1982), its lesions disrupted neither the acquisition nor the retention of TPOA. In contrast, lesions localized in the anterior insular neocortex impaired both CTA and TPOA learning (Lasiter et al. 1985). Such a discrepancy could reflect the fact that gustatory cortical areas within the insular region were not yet clearly delineated. The differences in Fos and Egr1 expressions reported here between the Li-O and $\mathrm{Na}-\mathrm{O}$ groups are in agreement with the lesion study of Lasiter et al. (1985). These changes were observed in the IC area as defined by the tract-tracing method of Nakashima et al. (2000), who specified the localization of the gustatory area already described in the dorsal part of the insular agranular cortex (Kosar et al. 1986). The IC has been shown to participate in taste processing and aversive memory storage. Thus, it cannot be put aside that the present increase in both Fos and Egr1 elicited by odor presentation in the Li-O rats could also reflect memories of taste and of visceral illness.

By using Fos and Egr1 immunocytochemistry, the present study allowed us to improve our knowledge regarding the neuronal network underlying TPOA retrieval. In rats that were previously submitted to an aversive conditioning, the presentation of the odor cue only elicited significant neuronal activity changes in some brain areas involved in the processing of odor or taste information and in limbic regions. Our data showed that the cerebral Fos pattern in aversive rats was not due to the sole $\mathrm{LiCl}$ injection but merely reflected activity linked to memory retrieval. In the EC, we noticed a differential expression of Fos and Egr1, which seems to indicate that the involvement of these markers in memory should not be similar. In the BLA, the dorsal Hipp, and the IC, we always provided evidence of a significant change in neuronal activation in aversive rats compared with the controls (either Na-O or P), whatever the marker employed. Such a finding led us to assume that these brain areas could play an important role in TPOA expression. In future experiments, it would be of interest to compare the neuronal activation elicited by TPOA retrieval with the one resulting from either odor or taste aversions considered separately.

\section{Materials and Methods}

\section{Subjects}

Fifty-six naive male SPF Wistar rats weighing 200-220g at the beginning of the experiment were used. All rats were treated in accordance with the European Communities council directive of November 24, 1986 (86/609/EEC). They were handled daily for 4 $\mathrm{d}$ in order to acclimate them to the experimenter. The animals were housed in individual cages, under a 12-h light/12-h dark cycle (lights on at 6:00 a.m.). Food and water were given ad libitum for $4 \mathrm{~d}$.

\section{Test chambers}

The rats were habituated to, trained, and tested in seven automated lickometers designed in the laboratory. The lickometer consisted of a Plexiglas cylindrical chamber (24-cm diameter, 40$\mathrm{cm}$ height), allowing observation of rat behavior during sessions. A drinking tube passing through an oval hole in the Plexiglas wall provided access to water. The cylinder was mounted on a platform with a stainless steel grid floor. A metal wire inside the tube and the steel floor was connected to an electronic device driven by a computer. It allowed us to record the number of licks during a session in the test chambers (Labview, International Instruments). On average, one lick delivered $3.1 \mu \mathrm{L}$ of liquid to the rat. On each glass tube, an odorized filter paper could be fixed at $1.5 \mathrm{~cm}$ from the aperture of the drinking tube.

\section{TPOA training procedure and animal groups}

Four days after their arrival, all the rats, except the home-cage control animals, were water-deprived. During a 7-d habituation phase, rats had access to water for $10 \mathrm{~min}$ per day in the test chambers. Rats were daily weighed to verify their adaptation to the water deprivation, and the number of licks was recorded during each session. On the eighth day, the rats were submitted to a conditioning trial that consisted of simultaneous presentation of filter paper odorized with $5 \mu \mathrm{L}$ of Geraniol (Sigma) and of a $0.1 \%$ saccharin solution for $10 \mathrm{~min}$ in the lickometer. Then they returned to their home-cages. Thirty minutes later, they received an intraperineal administration of either $\mathrm{LiCl}(0.2 \mathrm{M}, 20 \mathrm{~mL} / \mathrm{kg})$ or $\mathrm{NaCl}(0.9 \%, 20 \mathrm{~mL} / \mathrm{kg})$. This delay was chosen in accordance with the studies of Palmerino et al. (1980) and Ferry et al. (1995). During the two following days, rats were placed in the test chambers and had access to water for $10 \mathrm{~min}$. On the eleventh day, TPOA retrieval was assessed by a one-bottle test for $10 \mathrm{~min}$, and the water intake of each rat was recorded by the lickometer. The 
criterion of aversion expression chosen for all the groups tested was a decrease in the lick number of $30 \%$ at least per animal. All the trials were carried out in the middle of the light period (11:00 a.m. to 1:00 p.m.). ble 1).

The fifty-six rats used were divided into seven groups (Ta-

Four experimental groups were submitted to the TPOA training procedure: $\mathrm{Li}-\mathrm{O}(n=13$, weight $\pm \mathrm{SEM}=252 \mathrm{~g} \pm 15)$, $\mathrm{Na}-\mathrm{O}(n=12$, weight $\pm \mathrm{SEM}=259 \mathrm{~g} \pm 10), \mathrm{Li}-\mathrm{T}(n=7$, weight $=248 \mathrm{~g} \pm 20)$, and $\mathrm{Na}-\mathrm{T}(n=6$, weight $=260 \mathrm{~g} \pm 15)$ (Table 1). After TPOA acquisition, the $\mathrm{Li}-\mathrm{O}$ and $\mathrm{Li}-\mathrm{T}$ rats received an intraperineal injection of $\mathrm{LiCl}$, whereas the $\mathrm{Na}-\mathrm{O}$ and $\mathrm{Na}-\mathrm{T}$ rats were injected with saline solution.

The fifth experimental group named pseudo-conditioned rats $(\mathrm{P}-\mathrm{O}, n=7$, weight $\pm \mathrm{SEM}=249 \mathrm{~g} \pm 15)$ received a paired injection of $\mathrm{NaCl}$ after the presentation of odor and taste. Twenty-four hours later, the P-O rats received an unpaired injection of $\mathrm{LiCl}(0.2 \mathrm{M}, 20 \mathrm{~mL} / \mathrm{kg})$ in order to examine the effect of the $\mathrm{LiCl}$ induced illness on Fos and Egr1 expression.

On the day of TPOA retrieval, the number of licks was measured in the $\mathrm{Li}-\mathrm{O}$, the $\mathrm{Na}-\mathrm{O}$, and the $\mathrm{P}-\mathrm{O}$ groups in the presence of the odor. The number of licks was measured in the Li-T and $\mathrm{Na}-\mathrm{T}$ groups in the presence of the taste cue. The Li-T rats allowed us to check that rats were aversive to the saccharin taste tested alone and consequently, to assess TPOA phenomenon.

The sixth group consisted of home-cage control animals that had free access to water and were never manipulated $(C$ group, $n=7$ rats). Since our major aim was to investigate brain activation induced by the odor that acquired an aversive value via the TPOA conditioning procedure, only the $\mathrm{Li}-\mathrm{O}$, the $\mathrm{Na}-\mathrm{O}$, and the P-O groups were processed for Fos and Egr1 immunocytochemistry. The $\mathrm{C}$ rats were also used for immunocytochemistry in order to determine the basal level of Fos and Egr1 expression. The Li-T and Na-T groups were considered as behavioral controls of TPOA procedure, and their brains were not submitted to immunocytochemistry.

On the TPOA acquisition session, we injected the $\mathrm{LiCl} 30$ min after presentation of odor and taste cues. It was essential to ensure that with such a delay, the odor alone (without the saccharin) was not associated with the LiCl-induced illness whereas odor-taste stimulation could elicit TPOA. For this purpose, we used a seventh group: $O$ group $(n=4$, weight $=236 \mathrm{~g} \pm 19)$, which was submitted to a conditioned olfactory aversion (COA) procedure. The rats were stimulated by geraniol and drank water only. They received $\mathrm{LiCl}$ injection $30 \mathrm{~min}$ later and were tested after $2 \mathrm{~d}$ for geraniol aversion. These $\mathrm{O}$ rats were considered as behavioral controls, and their brains were not processed for immunocytochemistry.

\section{Fos and Egrl immunocytochemistry}

Animals of the Li-O, Na-O, and P-O groups were sacrificed 90 min after the end of the retrieval session, since this delay has been shown to be adequate for reaching a high concentration of Fos and Egr1 proteins (Chaudhuri et al. 2000). In parallel with these animals, the $\mathrm{C}$ rats were sacrificed without having been manipulated before. They were anesthetized deeply with a mixture of chloral hydrate and pentobarbital $(4 \mathrm{~mL} / \mathrm{kg})$ and then perfused transcardially with $200 \mathrm{~mL}$ of Ringer lactate containing $0.1 \%$ of heparin followed by $500 \mathrm{~mL}$ of ice-cold fixative (4\% paraformaldehyde, $0.1 \%$ glutaraldehyde, $0.2 \%$ picric acid in $0.1 \mathrm{M}$ phosphate buffer $[\mathrm{PB}]$ at $\mathrm{pH} 7.4$ ). Brains were removed from the skull and transferred in post-fixative solution ( $2 \%$ paraformaldehyde, $0.2 \%$ picric acid in $0.1 \mathrm{M} \mathrm{PB}$ at $\mathrm{pH} 7.4$ ) for $12 \mathrm{~h}$. After cryoprotection in $\mathrm{PB}$ containing 30\% sucrose for $48 \mathrm{~h}$, the brains were cut coronally $(25 \mu \mathrm{m})$ with a cryostat, and the sections were collected in $0.1 \mathrm{M}$ phosphate-buffered saline containing $0.3 \%$ Triton X-100 (PBST) and 0.1\% sodium azide (PBST-Az). Briefly, after elimination of endogenous peroxidase activity (incubation with $3 \%$ hydrogen peroxide), the floating sections were incubated for $60 \mathrm{~h}$ at $4^{\circ} \mathrm{C}$ in either a rabbit anti-Fos antibody (AB-5; Oncogene Science, diluted at 1:10,000 in 0.1 M PBST-Az) or a rabbit anti-Egr-1 antibody (Santa Cruz Biotechnology, diluted 1:5000 in 0.1 M PBST-Az). The sections were placed for $24 \mathrm{~h}$ at $4^{\circ} \mathrm{C}$ in biotinylated anti-rabbit IgG (Vector Laboratories) diluted 1:1000 in PBST. Then, the sections were incubated for $1 \mathrm{~h}$ in avidin-biotin-horseradish peroxydase complex reagent from an ABC Elite kit (Vector Laboratories). Between all steps, sections were rinsed several times with PBST. Lastly, sections reacted with 3-3'-diaminobenzidine $(0.02 \%)$ and $\mathrm{H}_{2} \mathrm{O}_{2}(0.003 \%)$ in $0.05 \mathrm{M}$ Tris-HCl solution ( $\mathrm{pH} 7.6)$ for $5 \mathrm{~min}$. The reaction was enhanced by adding nickel ammonium sulfate $(0.6 \%)$ that provided a black staining confined to the nucleus of the labeled cells. Then, the brain sections were rinsed in PBST-Az, mounted onto gelatincoated slides, dehydrated, and coverslipped with DePeX for light microscopy. Adjacent sections were counterstained with neutral red in order to delineate the brain structures.

\section{Data analysis}

Immunocytochemistry was performed on the seven rats of the $\mathrm{C}$ group and the seven rats of the P-O group but, due to a cryoprotection problem, only on eight and 11 rats of the $\mathrm{Li}-\mathrm{O}$ and $\mathrm{Na}-\mathrm{O}$ groups, respectively. The Paxinos and Watson atlas (Paxinos and Watson 1986) was used to identify brain areas. The PCx extends from $+12.7 \mathrm{~mm}$ to $+5.7 \mathrm{~mm}$ according to the interaural line. This paleocortex can be divided into anterior ( $\mathrm{PCX}-\mathrm{a})$ and posterior (PCX-p) parts, the boundary between them being at the level of the anterior commissure ( $+8.7 \mathrm{~mm}$ from interaural line). In each rat, we analyzed eight sections taken every $1000 \mu \mathrm{m}$ from +12.7 $\mathrm{mm}$ to $+5.7 \mathrm{~mm}$ along the whole rostrocaudal PCx extent. We also analyzed Fos and Egr1 expression in the dorsal Hipp (CA1, CA3, and DG) on two coronal sections located at $+6.2 \mathrm{~mm}$ and $+5.7 \mathrm{~mm}$ from the interaural line respectively and in the ventral Hipp on a coronal section located at $+3.4 \mathrm{~mm}$ from the interaural line. We further counted labeled cells in the BLA (Fig. 2A) and the

Table 1. Summary of experimental groups and TPOA conditioning procedures

\begin{tabular}{|c|c|c|c|c|c|c|}
\hline Group & Days 1-7 & Day 8 & Day 9 & Day 10 & Day 11 & Day 12 \\
\hline \multicolumn{7}{|c|}{ Experimental groups } \\
\hline $\begin{array}{l}\mathrm{Li}-\mathrm{O}, n=13 \\
\mathrm{Na}-\mathrm{O}, n=10 \\
\mathrm{P}-\mathrm{O}, n=7 \\
\mathrm{C}, n=7\end{array}$ & $\begin{array}{l}\text { habituation } \\
\text { habituation } \\
\text { habituation }\end{array}$ & $\begin{array}{l}\mathrm{O}+\mathrm{T} / \mathrm{LiCl} \\
\mathrm{O}+\mathrm{T} / \mathrm{NaCl} \\
\mathrm{O}+\mathrm{T} / \mathrm{NaCl}\end{array}$ & $\begin{array}{l}\text { water } \\
\text { water } \\
\text { LiCl }\end{array}$ & $\begin{array}{l}\text { water } \\
\text { water } \\
\text { water }\end{array}$ & $\begin{array}{l}\mathrm{O}+\text { water } \\
\mathrm{O}+\text { water } \\
\text { water }\end{array}$ & $\mathrm{O}$ + water \\
\hline \multicolumn{7}{|c|}{ Behavioral control groups } \\
\hline $\begin{array}{l}\mathrm{Li}-\mathrm{T}, n=7 \\
\mathrm{Na}-\mathrm{T}, n=6 \\
\mathrm{O}, n=4\end{array}$ & $\begin{array}{l}\text { habituation } \\
\text { habituation } \\
\text { habituation }\end{array}$ & $\begin{array}{l}\mathrm{O}+\mathrm{T} / \mathrm{LiCl} \\
\mathrm{O}+\mathrm{T} / \mathrm{NaCl} \\
\mathrm{O} / \mathrm{LiCl}\end{array}$ & $\begin{array}{l}\text { water } \\
\text { water } \\
\text { water }\end{array}$ & $\begin{array}{l}\text { water } \\
\text { water } \\
\text { water }\end{array}$ & $\begin{array}{l}\mathrm{T}+\text { water } \\
\mathrm{T}+\text { water } \\
\mathrm{O} \text { + water }\end{array}$ & \\
\hline
\end{tabular}

Experimental groups were processed for Fos and Egr1 immunocytochemistry. The odor stimulation (O) was geraniol. The taste stimulation (T) was sodium saccharin. Day 8 was the acquisition session; day 11, the retrieval session for the Li-O and the Na-O groups; and day 12, the retrieval session for the P-O group. LiCl: $0.2 \mathrm{M}, 20 \mathrm{~mL} / \mathrm{kg}$. NaCl: $0.9 \% ; 20 \mathrm{~mL} / \mathrm{kg}$. Home-cage rats $(\mathrm{C}, n=7)$ were sacrificed the same day (11 or 12$)$ as were the experimental rats. 
Ce, the EC (Fig. 3A), the IL (Fig. 4A), and the VLO (Fig. 3B) on sections corresponding to coronal planes located at $+5.7 \mathrm{~mm}$, $+4.2 \mathrm{~mm},+11.7 \mathrm{~mm}$, and $+12.7 \mathrm{~mm}$ from the interaural line, respectively. We counted immunoreactive cells in the gustatory region located in the dysgranular part of the IC (Fig. 4B), as defined by Nakashima et al. (2000) $(+9.7 \mathrm{~mm}$ from the interaural line). The single sections analyzed were representative of the regions examined. Detection level was adjusted individually to each section regarding the possible differences in background or staining intensities.

By means of a camera mounted on a Zeiss microscope, the brain sections were scanned via Photoshop software. Automatic quantification of Fos- and Egr1-labeled cells was performed by using the Optilab software.

Since the PCx, Hipp, and Amyg regions are well delineated, labeled cells were counted on the entire extent of these target regions within the selected coronal sections, and the data were expressed as mean number of labeled cells per rat. As the borders of the EC and of the neocortical areas are less easily determined, labeled cells were counted in a sample region (Figs. 3A,B, 4A,B) located according to the Paxinos and Watson atlas (1986), and data were expressed as a number of labeled cells per $\mathrm{mm}^{2}$.

Behavioral data were statistically analyzed by using a twoway ANOVA (one factor being the TPOA stages i.e., acquisition versus retrieval and the other being the experimental groups). Immunocytochemistry data in each brain structure considered were statistically analyzed by using a one-way ANOVA, the factor being the experimental groups. Student-Newman-Keuls test was used for post hoc statistical analysis (SAS Software, 8.2). We considered differences as significant when $P<0.05$.

\section{Acknowledgments}

The authors are grateful to Prof. S. Thornton for his helpful assistance with English. We also thank Mathieu Rossé and Michel Tavan for their helpful assistance with the lickometer elaboration. D.D. is a recipient of a Ministère de l'Education Nationale, de la Recherche et de la Technologie (MNERT) grant.

\section{References}

Alvarez, E.O. and Ruarte, B.R. 2004. Glutamic acid and histamine-sensitive neurons in the ventral hippocampus and the basolateral amygdale of the rat:functional interaction on memory and learning processes. Behav. Brain Res. 152: 209-219.

Batsell Jr., W.R. and Batson, J.D. 1999. Augmentation of taste conditioning by a preconditioned odor. J. Exp. Psychol. Anim. Behav. Process. 25: $374-388$.

Bermùdez-Rattoni, F., Grijalva, C.V., Kiefer, S.W., and Garcia, J. 1986. Flavor-illness aversions: The role of amygdala in the acquisition of taste-potentiated odor aversions. Physiol. Behav. 38: 503-508.

Bermùdez-Rattoni, F., Coburn, K.L., Fernandez, J., Chavez, A.F., and Garcia, J. 1987. Potentiation of odor by taste and odor aversions in rats are regulated by cholinergic activity of dorsal hippocampus. Pharmacol. Biochem. Behav. 26: 553-559.

Bernstein, I.L. 1991. Flavor aversion. In Smell and taste in health and disease (eds. T.V Getchell., et al.), pp. 417-428. Raven Press, New York, NY.

Bozon, B., Davis, S., and Laroche, S. 2002. Regulated transcription of the immediate-early gene Zif268: Mechanisms and gene dosage-dependent function in synaptic plasticity and memory formation. Hippocampus 12: 570-577.

Cardinal, R.N., Parkinson, J.A., Hall, J., and Everitt, B.J. 2002. Emotion and motivation: The role of the amygdala, ventral striatum, and prefrontal cortex. Neurosci. Biobehav. Rev. 26: 321-352.

Chabaud, P., Ravel, N., Wilson, D.A., Mouly, A.-M., Vigouroux, M., Farget, V., and Gervais, R. 2000. Exposure to behaviourally relevant odour reveals differential characteristics in rat central olfactory pathways as studied through oscillatory activities. Chem. Senses 25: $561-573$.

Chaudhuri, A., Zangenehpour, S., Rahbar-Dehgan, R., and Ye, F. 2000. Molecular maps of neural activity and quiescence. Acta Neurobiol. Exp. 60: 403-410.

Da Costa, A.P.C., Broad, K.D., and Kendrick, K.M. 1997. Olfactory memory and maternal behaviour-induced changes in c-fos and zif/268 mRNA expression in the sheep brain. Brain Res. Mol. Brain Res. 46: 63-73.

Datiche, F. and Cattarelli, M. 1996. Reciprocal and topographic connections between the piriform and prefrontal cortices in the Rat: A tracing study using the B subunit of the cholera toxin. Brain Res. Bull. 41: 391-398.

Datiche, F., Roullet, F., and Cattarelli, M. 2001. Expression of Fos in the piriform cortex after acquisition of olfactory learning: An immunohistochemical study in the rat. Brain Res. Bull. 55: 95-99.

Davis, S., Bozon, B., and Laroche, S. 2003. How necessary is the activation of the immediate-early gene zif268 in synaptic plasticity and learning? Behav. Brain Res. 142: 17-30.

Eichenbaum, H. 1998. Using olfaction to study memory. Ann. N.Y. Acad. Sci. 855: 657-669.

Ferry, B., Sandner, G., and Di Scala, G. 1995. Neuroanatomical and functional specificity of the basolateral amygdaloid nucleus in taste-potentiated odor aversion. Neurobiol. Learn. Mem. 64: 169-180.

Ferry, B., Oberling, P., Jarrard, L.E., and Di Scala, G. 1996. Facilitation of conditioned odor aversion by entorhinal cortex lesions in the rat. Behav. Neurosci. 110: 443-450.

Guzowski, J.F., Setlow, B., Wagner, E.K., and McGaugh, J.L. 2001. Experience-dependent gene expression in the rat hippocampus after spatial learning: A comparison of the immediate-early genes Arc, c-fos and zif268. J. Neurosci. 21: 5089-5098.

Haberly, L.B. and Bower, J. 1989. Olfactory cortex: Model circuit for study of associative memory? Trends Neurosci. 12: 258-264.

Hall, J., Thomas, K.L., and Everitt, B.J. 2001. Cellular imaging of Zif268 expression in the hippocampus and amygdala during contextual and cued fear memory retrieval: Selective activation of hippocampal CA1 neurons during the recall of contextual memories. J. Neurosci. 21: $2186-2193$.

Hatfield, T., Graham, P.W., and Gallagher, M. 1992. Taste-potentiated odor aversion learning: Role of the amygdaloid basolateral complex and central nucleus. Behav. Neurosci. 106: 286-293.

Herrera, D.G. and Robertson, H.A. 1996. Activation of c-fos in the brain. Prog. Neurobiol. 83: 83-107.

Hess, U.S., Lynch, G., and Gall, C.M. 1995. Changes in c-fos mRNA expression in Rat brain during odor discrimination learning: Differential involvement of hippocampal subfields CA1 and CA3. J. Neurosci. 15: 4786-4795.

Hess, U.S., Gall, C.M., Granger, R., and Lynch, G. 1997. Differential pattern of c-fos mRNA expression in amygdala during successive stages of odor discrimination learning. Learn. Mem. 4: 262-283.

Kaczmarek, L. 2002. c-Fos in learning: Beyond the mapping of neuronal activity. In Handbook of chemical neuroanatomy: IEG and inductible transcription factors of the central nervous system function and dysfucntion, Vol. 19. (eds. L. Kaczmarek and H.J. Herrera), pp. 189-215. Elsevier Science, New York.

Kaut, K.P., Bunsey, M.D., and Riccio, D.C. 2003. Olfactory learning and memory impairments following lesions to the hippocampus and perirhinal-entorhinal cortex. Behav. Neurosci. 117: 304-319.

Kiefer, S.W., Rusiniak, K.W., and Garcia, J. 1982. Flavor illness aversions: Gustatory neocortex ablations disrupt taste but not taste-potentiated odor cues. J. Comp. Psychol. 4: 540-548.

Kosar, E., Grill, J., and Norgren, R. 1986. Gustatory cortex in the rat, I: Physiological properties and cytoarchitecture. Brain Res. 379: 329-341.

Lamprecht, R., Hazvi, S., and Dudai, Y. 1997. cAMP response element-binding protein in the amygdala is required for long- but not short-term conditioned taste aversion memory. J. Neurosci. 17: 8443-8450.

Lasiter, P.S., Deems, D.A., and Garcia, J. 1985. Involvement of the anterior insular gustatory neocortex in the taste-potentiated odor aversion learning. Physiol. Behav. 34: 71-77.

Litaudon, P. and Cattarelli, M. 1996. Olfactory bulb repetitive stimulations reveal non-homogeneous distribution of the inhibitory processes in the rat piriform cortex. Eur. J. Neurosci. 8: 21-29.

Litaudon, P., Mouly, G., Sullivan, R., Gervais, R., and Cattarelli, M. 1997. Learning-induced changes in rat piriform cortex activity mapped using multisite recording with voltage sensitive dye. Eur. J. Neurosci. 9: 1593-1602.

McDonald, A.J. 1998. Cortical pathways to the mammalian amygdala. Prog. Neurobiol. 55: 257-332.

McGaugh, J.L. 2002. Memory consolidation and the amygdala: A systems perspective. Trends Neurosci. 25: 456-461.

Melia, K.R., Ryabinin, A.E., Schroeder, R., Bloom, F.E., and Wilson, M.C. 1994. Induction and habituation of immediate early gene expression in rat brain by acute and repeated restraint stress. J. Neurosci. 14: $5929-5938$.

Miller, J.S., Nonneman, A.J., Kelly, K.S., Neisewander, J.L., and Isaac, W.L. 1986. Disruption of neophobia, conditioned odor aversion and conditioned taste aversion in rats with hippocampal lesions. Behav. Neural Biol. 45: 240-253.

Morien, A., Garrard, L., and Rowland, N.E. 1999. Expression of Fos immunoreactivity in rat brain during dehydration: Effect of duration 
and timing of water deprivation. Brain Res. 816: $1-7$.

Mouly, A.M. and Gervais, R. 2002. Polysynaptic potentiation at different levels of rat olfactory pathways following learning. Learn. Mem. 9: $66-75$.

Nader, K., Schafe, G.E., and Le Doux, J.E. 2000. Fear memories require protein synthesis in the amygdala for reconsolidation after retrieval. Nature 406: 722-726.

Nakashima, M., Uemura, M., Yasui, K., Ozaki, H.S., Tabata, S., and Taen, A. 2000. An anterograde and retrograde tract-tracing study on the projections from the thalamic gustatory area in the rat: Distribution of neurons projecting to the insular cortex and amygdaloid complex. Neurosci. Res. 36: 297-309.

Navarro, M., Spray, K.J., Cubero, I., Thiele, T.E., and Bernstein, I.L. 2000. c-fos induction during conditioned taste aversion expression varies with the aversion strength. Brain Res. 887: 450-453.

Palmerino, C.C., Rusiniak, K.W., and Garcia, J. 1980. Flavor-illness aversions: The peculiar roles of odor and taste in memory for poison. Science 208: 753-755.

Paxinos, G. and Watson, C. 1986. The rat brain in stereotaxic coordinates. Academic Press, Sydney.

Rolls, E.T. 2001. The rules of formation of the olfactory representations found in the orbitofrontal cortex olfactory areas in primates. Chem. Senses 26: 595-604.

Roman, F., Staubli, U., and Lynch, G. 1987. Evidence for synaptic potentiation in a cortical network during learning. Brain Res. 418: 221-226.

Roullet, F., Lienard, F., Datiche, F., and Cattarelli, M. 2005. Fos protein expression in olfactory-related brain areas after learning and after reactivation of a slowly acquired olfactory discrimination task in the rat. Learn. Mem. 12: 307-317.

Schoenbaum, G., Chiba, A.A., and Gallagher, M. 1999. Neural encoding in orbitofrontal cortex and basolateral amygdala during olfactory discrimination learning. J. Neurosci. 19: 1876-1884.
Sesack, S.R., Roth, R.H., Deutch, A.Y., and Bunney, B.S. 1989. Topogaphical organization of the efferent projections of the medial prefrontal cortex in the Rat: An anterograde tract-tracing study with Phaseolus vulgaris Leucoagglutinin. J. Comp. Neurol. 290: 213-242.

Simpson, C.J. and Morris, B.J. 1995. Induction of c-fos and zif/268 gene expression in rat striatal neurons, following stimulation of D1-like dopamine receptors, involves protein kinase A and protein kinase C. Neuroscience 68: 97-106.

Spencer, C.M. and Houpt, T.A. 2001. Dynamics of c-fos and ICER mRNA expression in rat forebrain following lithium chloride injection. Brain Res. Mol. Brain Res. 93: 113-126.

Tanimoto, S., Nakagawa, T., Yamauchi, Y., Minami, M., and Satoh, M. 2003. Differential contributions of the basolateral and central nuclei of the amygdala in the negative affective component of chemical somatic and visceral pains in rats. Eur. J. Neurosci. 18: 2343-2350.

Wallenstein, G.V., Eichenbaum, H., and Hasselmo, M.E. 1998. The hippocampus as an associator of discontiguous events. Trends Neurosci. 21: 317-323.

Welzl, H., D'Adamo, P., and Lipp, H.-P. 2001. Conditioned taste aversion as a learning and memory paradigm. Behav. Brain Res. 125: $205-213$.

Yamada, Y., Hada, Y., Imamura, K., Mataga, N., Watanabe, Y., and Yamamoto, M. 1999. Differential expression of immediate-early-genes, c-fos and zif268, in the visual cortex of young rats: Effect of a noradrenergic neurotoxin on their expression. Neuroscience 92: 473-484.

Zinyuk, L.E., Datiche, F., and Cattarelli, M. 2001. Cell activity in the anterior piriform cortex during an olfactory learning in the rat. Behav. Brain Res. 124: 29-32.

Received August 4, 2004; accepted in revised form December 8, 2005.
160 Learning \& Memory www.learnmem.org 


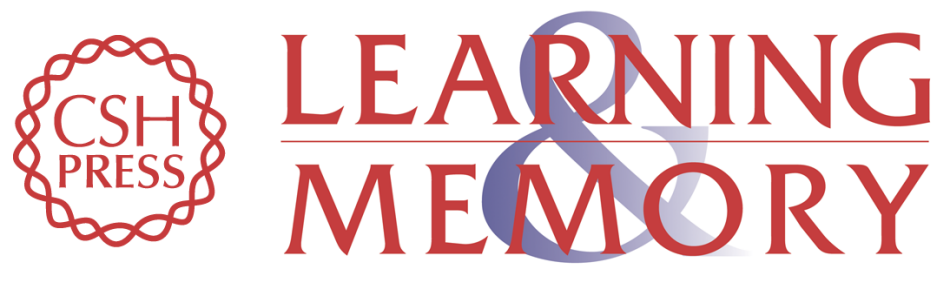

\section{Fos and Egr1 expression in the rat brain in response to olfactory cue after taste-potentiated odor aversion retrieval}

David Dardou, Frédérique Datiche and Martine Cattarelli

Learn. Mem. 2006, 13:

Access the most recent version at doi:10.1101//m.148706

References This article cites 50 articles, 10 of which can be accessed free at: http://learnmem.cshlp.org/content/13/2/150.full.html\#ref-list-1

License

Email Alerting Receive free email alerts when new articles cite this article - sign up in the box at the Service top right corner of the article or click here. 